OPEN ACCESS

Edited by:

John Isaacs,

Newcastle University,

United Kingdom

Reviewed by:

John Andrew Snowden,

Sheffield Teaching Hospitals NHS

Foundation Trust,

United Kingdom

Margit Zeher,

University of Debrecen, Hungary

${ }^{*}$ Correspondence:

Femke van Wijk

f.vanwijk@umcutrecht.n

these authors have contributed equally to this work as first

co-authors.

¥These authors have contributed equally to this work as last co-authors.

Specialty section:

This article was submitted

to Immunological Tolerance

and Regulation,

a section of the journal

Frontiers in Immunology

Received: 30 November 2017

Accepted: 27 March 2018

Published: 20 April 2018

Citation:

Lutter L, Spierings J, van Rhijn-

Brouwer FCC, van Laar JM and van Wijk F (2018) Resetting the T Cell

Compartment in Autoimmune

Diseases With Autologous

Hematopoietic Stem Cell

Transplantation: An Update.

Front. Immunol. 9:767.

doi: 10.3389/fimmu.2018.00767

\section{Resetting the T Cell Compartment in Autoimmune Diseases With Autologous Hematopoietic Stem Cell Transplantation: An Update}

\author{
Lisanne Lutter ${ }^{1 \dagger}$, Julia Spierings ${ }^{2 \dagger}$, Femke C. C. van Rhijn-Brouwer ${ }^{2,3}$, Jacob M. van Laar ${ }^{2 \ddagger}$ \\ and Femke van Wijk ${ }^{1 * \neq}$ \\ 'Laboratory of Translational Immunology, Department of Pediatrics, University Medical Center Utrecht, Utrecht, Netherlands, \\ ${ }^{2}$ Department of Rheumatology and Clinical Immunology, University Medical Center Utrecht, Utrecht, Netherlands, \\ ${ }^{3}$ Department of Nephrology and Hypertension, University Medical Center Utrecht, Utrecht, Netherlands
}

Autologous hematopoietic stem cell transplantation (aHSCT) for autoimmune diseases has been applied for two decades as a treatment for refractory patients with progressive disease. The rationale behind aHSCT is that high-dose immunosuppression eliminates autoreactive $T$ and $B$ cells, thereby resetting the immune system. Post-aHSCT the cytotoxic CD8 ${ }^{+} T$ cells normalize via clonal expansion due to homeostatic proliferation within a few months. CD4 ${ }^{+} \mathrm{T}$ cells recover primarily via thymopoiesis resulting in complete renewal of the T cell receptor (TCR) repertoire which requires years or never normalize completely. The increase in naïve T cells inducing immune tolerance, renewal of especially the regulatory TCR repertoire, and a less pro-inflammatory functional profile of the $\mathrm{CD}^{+} \mathrm{T}$ cells seem essential for successful immune reconstitution inducing long-term remission. There is currently a knowledge gap regarding the immune response in tissue sites post-aHSCT, as well as disease-specific factors that may determine remission or relapse. Future studies on lymphocyte dynamics and function may pave the way for optimized conditioning regimens with a more individualized approach.

Keywords: autologous hematopoietic stem cell transplantation, autoimmune disease, $\mathrm{T}$ cell reconstitution, $\mathrm{T}$ cell receptor repertoire, regulatory $\mathrm{T}$ cell

\section{INTRODUCTION}

Autoimmune diseases in general are characterized by a loss of immune tolerance. This results in generation and activation of autoreactive $\mathrm{T}$ and $\mathrm{B}$ cells leading to inflammation and consequently tissue damage. Autologous hematopoietic stem cell transplantation (aHSCT) for autoimmune diseases aims to eliminate autoreactive $\mathrm{T}$ and $\mathrm{B}$ cells and regenerate an immune system which is self-tolerant (1). The first reported aHSCT for an autoimmune disease, systemic sclerosis (SSc), was in 1996 by Tamm et al. (2). Since then, aHSCT has also been increasingly applied for treatmentrefractory patients with other progressive autoimmune diseases, including multiple sclerosis (MS), Crohn's disease, and juvenile idiopathic arthritis (JIA). Especially for SSc and MS, the clinical efficacy has been demonstrated in phase II and III clinical trials (3-6), whereas for Crohn's disease

Abbreviations: aHSCT, autologous hematopoietic stem cell transplantation; ATG, anti-thymocyte globulin; CLTA-4, cytotoxic T lymphocyte-associated protein 4; CYC, cyclophosphamide; DM type I, type I diabetes mellitus; GITR, glucocorticoid-induced TNFR-related protein; IL, interleukin; MS, multiple sclerosis; PD, pharmacodynamic; PD-1, programmed cell death-1 protein; PK, pharmacokinetic; SSc, systemic sclerosis; TCR, T cell receptor; Th, T helper; Treg, regulatory T-cell. 
the clinical efficacy is much more variable $(5,7)$. In JIA, the need for transplantation has declined since the appearance of effective therapies (8). Though international clinical guidelines have acknowledged the value of aHSCT for selected patients with refractory disease, it generally remains a rescue therapy due to the invasive nature and risk of treatment-related mortality, as well as the continuous development of new therapeutics (9). Although aHSCT is not a curative treatment, long-term remission can be achieved, and patients with relapses are usually responsive to conventional treatment again (10).

Autologous HSCT treatment starts with mobilization of hematopoietic stem cells into the peripheral circulation using cyclophosphamide (CYC) and recombinant G-CSF. This enables apheresis of stem cells. CD34 ${ }^{+}$selection, to purge the collected stem cells of $\mathrm{T}$ cells can be performed, although it is unclear whether it has clinical benefits. The next step is the immunoablative conditioning phase. In autoimmune disease high-dose CYC and occasionally, in vivo purging is performed by systemic administration of antibodies such as anti-thymocyte globulin (ATG) or rituximab. Finally, the hematopoietic stem cells are reinfused, which accelerates hematopoietic reconstitution (1). Exactly how aHSCT rewires a faulty immune system is still unknown. It is unclear which cells need to be depleted and which ones are important to keep. Additionally, not all cells are depleted by aHSCT and residing cells may pose a risk of early disease relapse. Understanding the quantitative and qualitative lymphocyte dynamics in relation to clinical outcome is therefore crucial to design less toxic but efficacious targeted therapies aimed at resetting the immune balance. Here, we will discuss the latest findings on $\mathrm{T}$ cell reconstitution post-aHSCT for autoimmune diseases, including $\mathrm{T}$ cell receptor (TCR) repertoire changes, and how these findings relate to clinical efficacy.

\section{T CELL RECONSTITUTION}

The innate immune system recovers within weeks post-aHSCT, in contrast to the reconstitution of the adaptive immune system which can take years [for recent in-depth reviews, see Ref. $(10-14)]$.

Generally, the peripheral lymphocyte count and subsets at baseline, before aHSCT, are similar to healthy controls. Patients with MS that clinically responded to aHSCT in a phase II clinical trial, had higher memory $\mathrm{CD}^{+}$and $\mathrm{CD}^{+} \mathrm{T}$ cell counts preaHSCT compared with non-responders (15) and for SSc the same trend in higher complete $\mathrm{CD}^{+}$and $\mathrm{CD}^{+} \mathrm{T}$ cell counts preaHSCT for the responders was observed (16). This might suggest that patients with increased peripheral $\mathrm{CD} 4^{+} \mathrm{T}$ cell activation pre-aHSCT may respond better to aHSCT.

\section{CD8 $^{+}$T Cells}

Following aHSCT, the lymphopenic environment drives lymphopenia-induced proliferation. Cytotoxic $\mathrm{CD}^{+} \mathrm{T}$ cells are the first $\mathrm{T}$ cells to normalize and the ratio of naïve to memory $\mathrm{CD}^{+} \mathrm{T}$ cells remains constant post-aHSCT. In patients with MS early expression (within 6 months) of the inhibitory molecule programmed cell death-1 protein (PD-1) on $\mathrm{CD}^{+} \mathrm{T}$ cells correlated with a good clinical response post-aHSCT (17). Early PD-1 expression is likely protective by maintaining peripheral immune tolerance (18).

\section{CD4 $^{+}$T Cells}

$\mathrm{CD}^{+} \mathrm{T}$ cell reconstitution is more dependent on thymopoiesis, and $\mathrm{CD}^{+} \mathrm{T}$ cell numbers often requires years to normalize. As a consequence, there is an inversed CD4/CD8 $\mathrm{T}$ cell ratio. Furthermore, following aHSCT the residual naive T cells disappear, seemingly due to rapid maturation to effector memory $\mathrm{T}$ cells, resulting in decreased naive and increased effector memory $\mathrm{T}$ cells in the first 3 months post-aHSCT (17). Naive $\mathrm{CD}^{+} \mathrm{T}$ cells increase upon thymic reactivation after several months, which results in a relative decrease of central memory $\mathrm{CD}^{+} \mathrm{T}$ cells. The $\mathrm{CD} 4^{+} \mathrm{T}$ cell compartment also reshapes postaHSCT compared with baseline. Unfortunately, correlations with clinical outcomes were ambiguous. In a single arm study of 11 SSc patients receiving aHSCT, naive and memory $\mathrm{CD}^{+} \mathrm{T}$ cells remained decreased during the follow-up period of 3 years (19). All patients had a good response to treatment. Decreased CD4 ${ }^{+}$ $\mathrm{T}$ cells after 9 months in both responders and non-responders was reported in another study in SSc patients (20). Faster increase of $\mathrm{CD} 4^{+} \mathrm{T}$ cells in non-responders was seen in two studies in SSc patients $(16,20)$. Furthermore, while T helper (Th) 1 and 2 cells remain unaltered in frequency, Th17 cells diminish below baseline post-aHSCT, but normalize after 6 months. Functionally, post-aHSCT the Th1 and Th17 cells show a reduced interferon- $\gamma$ and interleukin (IL)-17 response, respectively (12, 15, 17, 21-25). Above mentioned changes are also observed on transcriptional level, with the transcriptional program of $\mathrm{CD}^{+} \mathrm{T}$ cells normalizing within 2 years post-aHSCT, whereas the transcriptional program of $\mathrm{CD}^{+} \mathrm{T}$ cells significantly changes post-aHSCT but does not normalize (26).

\section{Regulatory T Cells}

Data regarding regulatory $\mathrm{T}$ cells is contradicting, with most studies observing an increase of regulatory $\mathrm{T}$ cells following transplantation, usually temporarily, although in some studies no changes or decreased relative frequencies are found $(12,15$, $17,21-25,27,28)$. Regulatory T cells of clinically responding SSc patients had increased levels of the immune regulators cytotoxic T lymphocyte-associated protein 4 (CTLA-4), a negative regulator of $\mathrm{T}$ cell function, and glucocorticoid-induced TNFR-related protein compared with non-responders (28). Upregulation of CTLA- 4 on regulatory T cells post-aHSCT in both MS and type 1 diabetes mellitus (DM type 1) patients, and increased regulatory $\mathrm{T}$ cell functional marker expression such as IL-10 and transforming growth factor- $\beta$ in DM type 1 patients post-aHSCT has also been observed, but in these cases without positive association with the clinical outcome $(17,24)$. In mice, graft-derived regulatory $\mathrm{T}$ cells were shown to have superior suppressive function compared with regulatory $\mathrm{T}$ cells that survived conditioning (29). In conclusion, renewal of the regulatory $\mathrm{T}$ cell compartment seems essential for long-term restoration of immune homeostasis, with qualitative changes of regulatory $\mathrm{T}$ cells having a more profound impact than quantitative changes, although this may differ per autoimmune disease. 


\section{TCR REPERTOIRE POST-TRANSPLANTATION}

Initially, lymphopenia-induced proliferation following transplantation results in clonal expansion of residual $\mathrm{T}$ cells. Restoration of a fully competent $\mathrm{T}$ cell compartment with a diverse TCR repertoire is depending on thymic output that starts 3-6 months following HSCT. In SSc, the total TCR repertoire diversifies post-aHSCT, irrespective of the clinical outcome (16), although with a trend to a more diverse repertoire in patients without a relapse (20). However, a recent study in SSc patients did show increased TCR diversity at 1 year post-aHSCT in responders compared with non-responders. Furthermore, low overlap in TCR $\beta$ (CDR3) clonotype before and after transplantation was observed in responders (25\% overlap) but not in nonresponders ( $60 \%$ overlap) (28). This suggests that renewal of the TCR repertoire is important for the re-establishment of immune homeostasis. The difference in TCR repertoire outcome might be explained by use of ATG in the latter study, whereas this was not used or optional in addition to CYC in the first two studies $(16,20,28)$.

In MS patients renewal of the $\mathrm{CD}^{+} \mathrm{T}$ cell repertoire was observed, with the dominant $\mathrm{CD} 4^{+} \mathrm{T}$ cell clones present at baseline not detectable following transplantation. In contrast, dominant $\mathrm{CD}^{+} \mathrm{T}$ cell clones detectable pre-aHSCT remained present postaHSCT, and were clonally expanded $(21,22)$. Especially early on, non-responding MS patients had a less diverse TCR repertoire than patients without relapse, though this difference had disappeared at 1 year post-transplantation (22). In JIA and juvenile dermatomyositis patients, the $\mathrm{CD} 4{ }^{+} \mathrm{T}$ cell and FOXP3 regulatory TCR repertoire were studied separately. Compared with baseline, responders had a far more diverse regulatory $\mathrm{T}$ cell repertoire post-aHSCT. In contrast, patients that experienced a relapse showed an even more oligoclonal repertoire compared with baseline. The $\mathrm{CD} 4^{+} \mathrm{TCR}$ repertoire also diversified in responders, but less pronounced than in the regulatory $\mathrm{T}$ cell compartment. Similarly to MS patients, no overlapping $\mathrm{CD} 4^{+}$TCRs were found pre- and post-aHSCT (29).

In conclusion, even though these studies were performed in patients with different autoimmune diseases there is a consistent pattern. The TCR repertoire of $\mathrm{CD}^{+} \mathrm{T}$ cells remains relatively oligoclonal, and the same dominant TCR clones can be observed pre- and post-aHSCT without noticeable clinical consequences. This suggests these $\mathrm{CD} 8^{+} \mathrm{T}$ cells are not self-reactive, or are but unable to induce disease activity following transplantation. The $\mathrm{CD}^{+} \mathrm{T}$ cells are characterized by a complete renewal of the TCR repertoire, and especially an increased TCR diversity for regulatory $\mathrm{T}$ cells seems important for a successful induction of remission post-transplantation.

\section{TISSUE T CELL DEPLETION}

Almost all data regarding the immune reconstitution following aHSCT are based on cells in circulation. However, the aberrant inflammation in autoimmune diseases is primarily located in tissue sites. Recently, it was shown that in intestinal tissue of patients with refractory Crohn's disease the TCR repertoire diversifies post-aHSCT. Approximately $20 \%$ of TCR sequences were detected pre- and 6 months to 1 year post-aHSCT, demonstrating a vast resetting of the TCR repertoire (30). The clinical impact of a local expanding TCR repertoire has not been established, but these preliminary data show a local immune response occurs following transplantation. In SSc, the TCR repertoire in affected skin is strongly oligoclonal (31). Following aHSCT, there is a reduction of skin fibrosis in responding patients (follow-up time of approximately 6 years) (16), but whether this is associated with the generation of a polyclonal TCR repertoire in the skin is unknown.

Of note, the extent of tissue penetration of ATG and other immunosuppressive agents is unclear. In mice, depletion of T cells by ATG is less efficient in peripheral lymphoid organs compared with the blood (32). It is not unlikely that tissue resident memory $\mathrm{T}$ cells, antigen-experienced $\mathrm{T}$ cells permanently residing in barrier tissues (33), are not fully depleted. Is there a need for (more) profound tissue immune cell depletion, or does maintenance of the tissue immune cells protect patients after conditioning to not succumb to infection? Future studies may shed light on the extend of tissue lymphocyte depletion following conditioning and whether this affects clinical outcome.

\section{THE CONDITIONING REGIMEN AND T CELL RECONSTITUTION}

The conditioning regimen is an important factor in immune reconstitution post-aHSCT. In a study in $13 \mathrm{MS}$ patients, using CYC and ATG for conditioning, the CD4/CD8 ratio remained lower than in healthy controls, and naïve $\mathrm{CD} 4^{+} \mathrm{T}$ cells normalized 2 years post-aHSCT (23). In contrast, in another study in MS patients with CYC and total body irradiation employed for conditioning the CD4/CD8 ratio normalized at 2 years post-aHSCT, and an overshoot of naive $\mathrm{CD} 4^{+} \mathrm{T}$ cells was observed (21). In the latter study, all patients remained in remission during the follow-up of 2-3 years, whereas in the first study $30 \%$ experienced a relapse within 3 years post-aHSCT. However, these differences might also be partially explained by differential patient selection. ATG is often implemented in the conditioning regimen (13) and can severely affect immune reconstitution. As a polyclonal antibody it targets a plethora of immune cells and induces both direct and indirect cytotoxicity. Interestingly, a recent study on ATG exposure and clinical outcome in an allogeneic HSCT setting suggests that ATG dosing should be based on lymphocyte count rather than body-weight (34). Currently, ATG dosing in aHSCT patients is not individualized and monitoring both ATG levels and lymphocytes counts could be a helpful addition to define the optimal dosing strategy.

Long-term impact of an incomplete $\mathrm{T}$ (and B) cell reconstitution is unknown. While reliable data regarding incomplete immunological reconstitution post-HSCT is lacking, there are indications that this is not associated with long-term morbidity. A for instance, a study assessed outcomes in rheumatoid arthritis patients that received Alemtuzumab, an anti-CD52 antibody targeting primarily $\mathrm{T}$ and $\mathrm{B}$ cells. Follow-up for 20-25 years shows an incomplete reconstitution of $\mathrm{T}$ and $\mathrm{B}$ cells, especially central memory $\mathrm{CD} 4^{+}$and $\mathrm{CD} 8^{+} \mathrm{T}$ cells and naïve $\mathrm{B}$ cell numbers 
remain reduced. The incomplete reconstitution, however, was not associated with differences in mortality, morbidity, or vaccine response when compared with rheumatoid arthritis patients that have received standard care (35). These data emphasize the need to understand the normal immune reconstitution to establish optimal conditioning regimens, as well as to compare different autoimmune diseases to identify disease-specific factors that might predict long-term remission or a relapse.

\section{CLINICAL HETEROGENEITY INFLUENCING IMMUNE RECONSTITUTION}

Unfortunately, interpretation of changes in T cell compartment after aHSCT is complicated by heterogeneity in type of autoimmune disease, conditioning regimens, patient selection, graft manipulation, post-transplantation treatment, and age- or treatment-dependent thymic involution. For instance, in some studies patients have severe immune dysregulation resulting in severe and/or progressive, treatment resistant disease. These patients have often received most available immunosuppressive therapies including biologicals before aHSCT, while in other settings (e.g., SSc) aHSCT is performed relatively early in disease. Another possible confounding factor is graft manipulation by selection of $\mathrm{CD} 34^{+}$stem cells. The influence of this selection on immune reconstitution is reported in several studies, and although broadly used in treatments, there is conflicting evidence of its benefits (36-38). Finally, the numbers of patients included in clinical studies generally are too small to compare outcome between responders and non-responders. Despite all confounding factors, standardized (extensive) phenotypic characterization of $\mathrm{T}$ cell reconstitution would be an important step forward in elucidating $\mathrm{T}$ cell reconstitution and relating it to treatment regimens and outcome.

\section{CONCLUSION AND FUTURE PERSPECTIVES}

In the past 20 years, aHSCT has been applied for severe refractory autoimmune diseases but a comprehensive understanding

\section{REFERENCES}

1. Sykes M, Nikolic B. Treatment of severe autoimmune disease by stem-cell transplantation. Nature (2005) 435:620-7. doi:10.1038/ nature 03728

2. Tamm M, Gratwohl A, Tichelli A, Perruchoud AP, Tyndall A. Autologous haemopoietic stem cell transplantation in a patient with severe pulmonary hypertension complicating connective tissue disease. Ann Rheum Dis (1996) 55:779-80. doi:10.1136/ard.55.10.779

3. EBMT. EBMT Annual Report 2015. (2016). Available from: http://www.ebmt. org/ebmt/documents/ebmt-annual-report-2015 (Accessed: March, 2016).

4. van Laar JM, Farge D, Sont JK, Naraghi K, Marjanovic Z, Larghero J, et al. Autologous hematopoietic stem cell transplantation vs intravenous pulse cyclophosphamide in diffuse cutaneous systemic sclerosis. JAMA (2014) 311:2490. doi:10.1001/jama.2014.6368

5. Lindsay JO, Allez M, Clark M, Labopin M, Ricart E, Rogler G, et al. Autologous stem-cell transplantation in treatment-refractory Crohn's disease: an analysis of pooled data from the ASTIC trial. Lancet Gastroenterol Hepatol (2017) 2:399-406. doi:10.1016/S2468-1253(17)30056-0 of the immune reconstitution and the link with clinical outcome is still missing. Data suggest that the increase in naïve $\mathrm{T}$ cells, renewal of especially the regulatory TCR repertoire, and a less pro-inflammatory functional profile of the $\mathrm{CD}^{+} \mathrm{T}$ cells are essential for successful immune reconstitution and the induction of long-term remission. Future studies on lymphocyte dynamics and function may pave the way for optimized conditioning regimens with a more individualized approach.

Important outstanding questions regarding the immune reconstitution following transplantation include: (1) What is the most effective conditioning regime for each autoimmune disease? This possibly depends on which immune cells are important in the pathogenesis, and the tissue(s) where the disease manifests, thus differ per autoimmune disease. (2) Is a personalized approach to the conditioning regime, depending on the immune status pre-aHSCT, needed to improve the clinical outcome? The recent observation that in a hematologic malignancy setting ATG dosing should be based on lymphocyte count may also apply to autoimmune settings. Extensive monitoring of immune depletion/reconstitution in combination with pharmacokinetic/ pharmacodynamic modeling can contribute to the development of pre- and post-transplantation precision treatment. (3) What is the local tissue effect of the conditioning regimen? It is not clear to which extent for example ATG penetrates all tissues to deplete tissue $\mathrm{T}$ cells, and it is unclear if and to what extent residual tissue $\mathrm{T}$ cells contribute to relapses of disease. Together, future studies may shed light on the fine balance between effectively destroying and renewing the immune system, but with limited toxicity.

\section{AUTHOR CONTRIBUTIONS}

LL, JS, FR-B, JL, and FW have discussed, written, and edited the manuscript.

\section{FUNDING}

FW is supported by a VIDI grant (91714332) from The Netherlands Organization for Health Research and Development (ZonMw).

6. Atkins HL, Bowman M, Allan D, Anstee G, Arnold DL, Bar-Or A, et al. Immunoablation and autologous haemopoietic stem-cell transplantation for aggressive multiple sclerosis: a multicentre single-group phase 2 trial. Lancet (2016) 388:576-85. doi:10.1016/S0140-6736(16)30169-6

7. Snowden JA, Panes J, Alexander T, Allez M, Ardizzone S, Dierickx D, et al. Autologous haematopoietic stem cell transplantation (AHSCT) in severe Crohn's disease: a review on behalf of ECCO and EBMT. J Crohns Colitis (2018) 12:476-88. doi:10.1093/ecco-jcc/jjx184

8. Snowden JA, Badoglio M, Labopin M, Giebel S, McGrath E, Marjanovic Z, et al. Evolution, trends, outcomes, and economics of hematopoietic stem cell transplantation in severe autoimmune diseases. Blood Adv (2017) 1:2742-55. doi:10.1182/bloodadvances.2017010041

9. Kowal-Bielecka O, Fransen J, Avouac J, Becker M, Kulak A, Allanore Y, et al. Update of EULAR recommendations for the treatment of systemic sclerosis. Ann Rheum Dis (2017) 76:1327-39. doi:10.1136/annrheumdis2016-209909

10. Swart JF, Delemarre EM, van Wijk F, Boelens J-J, Kuball J, van Laar JM, et al. Haematopoietic stem cell transplantation for autoimmune diseases. Nat Rev Rheumatol (2017) 13:244-56. doi:10.1038/nrrheum.2017.7 
11. Arruda LCM, Clave E, Moins-Teisserenc H, Douay C, Farge D, Toubert A. Resetting the immune response after autologous hematopoietic stem cell transplantation for autoimmune diseases. Curr Res Transl Med (2016) 64: 107-13. doi:10.1016/j.retram.2016.03.004

12. Collins F, Kazmi M, Muraro PA. Progress and prospects for the use and the understanding of the mode of action of autologous hematopoietic stem cell transplantation in the treatment of multiple sclerosis. Expert Rev Clin Immunol (2017) 13:611-22. doi:10.1080/1744666X.2017.1297232

13. Muraro PA, Martin R, Mancardi GL, Nicholas R, Sormani MP, Saccardi R. Autologous haematopoietic stem cell transplantation for treatment of multiple sclerosis. Nat Rev Neurol (2017) 13:391-405. doi:10.1038/nrneurol.2017.81

14. van Rhijn-Brouwer FCC, Spierings J, van Laar JM. Autologous hematopoietic stem cell transplantation in systemic sclerosis: a reset to tolerance? Immunol Lett (2017) 195:88-96. doi:10.1016/j.imlet.2017.11.005

15. Karnell FG, Lin D, Motley S, Duhen T, Lim N, Campbell DJ, et al. Reconstitution of immune cell populations in multiple sclerosis patients after autologous stem cell transplantation. Clin Exp Immunol (2017) 189:268-78. doi:10.1111/cei.12985

16. Farge D, Arruda LCM, Brigant F, Clave E, Douay C, Marjanovic Z, et al. Long-term immune reconstitution and $\mathrm{T}$ cell repertoire analysis after autologous hematopoietic stem cell transplantation in systemic sclerosis patients. J Hematol Oncol (2017) 10:21. doi:10.1186/s13045-016-0388-5

17. Arruda LCM, de Azevedo JTC, de Oliveira GLV, Scortegagna GT, Rodrigues ES, Palma PVB, et al. Immunological correlates of favorable long-term clinical outcome in multiple sclerosis patients after autologous hematopoietic stem cell transplantation. Clin Immunol (2016) 169:47-57. doi:10.1016/j.clim.2016. 06.005

18. Jin H-T, Ahmed R, Okazaki T. Role of PD-1 in regulating T-cell immunity. Curr Top Microbiol Immunol (2011) 350:17-37. doi:10.1007/82_2010_116

19. Tsukamoto H, Nagafuji K, Horiuchi T, Mitoma H, Niiro H, Arinobu Y, et al. AnalysisofimmunereconstitutionafterautologousCD34+stem/progenitorcell transplantation for systemicsclerosis: predominant reconstitution of Th1CD4+ T cells. Rheumatology (Oxford) (2011) 50:944-52. doi:10.1093/rheumatology/ keq414

20. Farge D, Henegar C, Carmagnat M, Daneshpouy M, Marjanovic Z, Rabian C, et al. Analysis of immune reconstitution after autologous bone marrow transplantation in systemic sclerosis. Arthritis Rheum (2005) 52:1555-63. doi:10.1002/art.21036

21. Muraro PA, Douek DC, Packer A, Chung K, Guenaga FJ, Cassiani-Ingoni R, et al. Thymic output generates a new and diverse TCR repertoire after autologous stem cell transplantation in multiple sclerosis patients. J Exp Med (2005) 201:805-16. doi:10.1084/jem.20041679

22. Muraro PA, Robins H, Malhotra S, Howell M, Phippard D, Desmarais C, et al. Brief report $\mathrm{T}$ cell repertoire following autologous stem cell transplantation for multiple sclerosis. J Clin Invest (2014) 124:1168-72. doi:10.1172/JCI71691DS1

23. Cull G, Hall D, Fabis-Pedrini M, Carroll W, Forster L, Robins F, et al. Lymphocyte reconstitution following autologous stem cell transplantation for progressive MS. Mult Scler J Exp Transl Clin (2017) 3:205521731770016. doi:10.1177/2055217317700167

24. Ye L, Li L, Wan B, Yang M, Hong J, Gu W, et al. Immune response after autologous hematopoietic stem cell transplantation in type 1 diabetes mellitus. Stem Cell Res Ther (2017) 8:90. doi:10.1186/s13287-017-0542-1

25. Malmegrim KCR, de Azevedo JTC, Arruda LCM, Abreu JRF, Couri CEB, de Oliveira GLV, et al. Immunological balance is associated with clinical outcome after autologous hematopoietic stem cell transplantation in type 1 diabetes. Front Immunol (2017) 8:167. doi:10.3389/fimmu.2017.00167

26. de Paula ASA, Malmegrim KCR, Panepucci RA, Brum DS, Barreira AA, Carlos Dos Santos A, et al. Autologous haematopoietic stem cell transplantation reduces abnormalities in the expression of immune genes in multiple sclerosis. Clin Sci (Lond) (2015) 128:111-20. doi:10.1042/CS20140095
27. Danikowski KM, Jayaraman S, Prabhakar BS. Regulatory T cells in multiple sclerosis and myasthenia gravis. J Neuroinflammation (2017) 14:117. doi:10.1186/s12974-017-0892-8

28. Arruda LCM, Malmegrim KCR, Lima-Junior JR, Clave E, Dias JBE, Moraes DA, et al. Immune rebound associates with a favorable clinical response to autologous HSCT in systemic sclerosis patients. Blood Adv (2018) 2:126-41. doi:10.1182/bloodadvances.2017011072

29. Delemarre EM, Van Den Broek T, Mijnheer G, Meerding J, Wehrens EJ, Olek S, et al. Autologous stem cell transplantation aids autoimmune patients by functional renewal and TCR diversification of regulatory T cells. Blood (2016) 127:91-102. doi:10.1182/blood-2015-06-649145

30. Le Bourhis L, Corraliza A, Auzolle C, Ricart E, Hawkey C, Lindsay JO, et al. OP004 Resetting of the mucosal $\mathrm{T}$ cell repertoire after hematopoietic stem cell transplantation in refractory Crohn's disease. J Crohns Colitis (2017) 11(suppl_1):S2-S3. doi:10.1093/ecco-jcc/jjx002.003

31. Sakkas LI, Xu B, Artlett CM, Lu S, Jimenez SA, Platsoucas CD. Oligoclonal $\mathrm{T}$ cell expansion in the skin of patients with systemic sclerosis. JImmunol (2002) 168:3649-59. doi:10.4049/jimmunol.168.7.3649

32. Xia C-Q, Chernatynskaya AV, Wasserfall CH, Wan S, Looney BM, Eisenbeis S, et al. Anti-thymocyte globulin (ATG) differentially depletes naïve and memory $\mathrm{T}$ cells and permits memory-type regulatory $\mathrm{T}$ cells in nonobese diabetic mice. BMC Immunol (2012) 13:70. doi:10.1186/1471-2172-13-70

33. Park CO, Kupper TS. The emerging role of resident memory $\mathrm{T}$ cells in protective immunity and inflammatory disease. Nat Med (2015) 21:688-97. doi: $10.1038 / \mathrm{nm} .3883$

34. Admiraal R, van Kesteren C, Jol-van der Zijde CM, Lankester AC, Bierings MB, Egberts TCG, et al. Association between anti-thymocyte globulin exposure and CD4+ immune reconstitution in paediatric haemopoietic cell transplantation: a retrospective pharmacodynamic cohort analysis. Lancet Haematol (2015) 2:e194-203. doi:10.1016/S2352-3026(15)00045-9

35. Cooles FAH, Anderson AE, Drayton T, Harry RA, Diboll J, Munro L, et al. Immune reconstitution 20 years after treatment with alemtuzumab in a rheumatoid arthritis cohort: implications for lymphocyte depleting therapies. Arthritis Res Ther (2016) 18:302. doi:10.1186/s13075-016-1188-6

36. Moore J, Brooks P, Milliken S, Biggs J, Ma D, Handel M, et al. A pilot randomized trial comparing CD34-selected versus unmanipulated hemopoietic stem cell transplantation for severe, refractory rheumatoid arthritis. Arthritis Rheum (2002) 46:2301-9. doi:10.1002/art.10495

37. Oliveira MC, Labopin M, Henes J, Moore J, Papa ND, Cras A, et al. Does ex vivo CD34+ positive selection influence outcome after autologous hematopoietic stem cell transplantation in systemic sclerosis patients? Bone Marrow Transplant (2015) 51(4):501-5. doi:10.1038/bmt.2015.299

38. Alchi B, Jayne D, Labopin M, Kotova O, Sergeevicheva V, Alexander T, et al. Autologous haematopoietic stem cell transplantation for systemic lupus erythematosus: data from the European Group for Blood and Marrow Transplantation registry. Lupus (2013) 22:245-53. doi:10.1177/ 0961203312470729

Conflict of Interest Statement: The authors declare that the research was conducted in the absence of any commercial or financial relationships that could be construed as a potential conflict of interest.

Copyright (c) 2018 Lutter, Spierings, van Rhijn-Brouwer, van Laar and van Wijk. This is an open-access article distributed under the terms of the Creative Commons Attribution License (CC BY). The use, distribution or reproduction in other forums is permitted, provided the original author(s) and the copyright owner are credited and that the original publication in this journal is cited, in accordance with accepted academic practice. No use, distribution or reproduction is permitted which does not comply with these terms. 